\title{
Survival of participating and nonparticipating limb amputees in prospective study: Consequences for research
}

\author{
Joline C. Bosmans, PhD; ${ }^{1-2 *}$ Jan H. B. Geertzen, PhD; ${ }^{1-2}$ Harald J. Hoekstra, PhD; ${ }^{3}$ Pieter U. Dijkstra, PhD ${ }^{1-2,4}$ \\ ${ }^{1}$ Department of Rehabilitation Medicine, University Medical Center Groningen (UMCG), University of Groningen, the \\ Netherlands; ${ }^{2}$ Graduate School for Health Research, UMCG, University of Groningen, the Netherlands; Departments \\ of ${ }^{3}$ Surgery and ${ }^{4}$ Oral and Maxillofacial Surgery, UMCG, University of Groningen, the Netherlands
}

\begin{abstract}
This study quantified selection by analyzing the survival rate of the participants and nonparticipants in a 4-year prospective, multicenter cohort study. In addition, the differences between these groups were analyzed. Surgeons of six hospitals in the northern Netherlands referred, in total, 225 patients to the study. Of these patients, $60 \%(n=134)$ participated in the prospective study by filling in questionnaires; the others (nonparticipants) were followed over time through their records. No significant differences were found in sex and level of amputation between participants and nonparticipants; however, of the two groups, nonparticipants were significantly older. Reason for amputation was peripheral vascular disease (PVD) for 67\% ( $n=$ 90) of the participants and $82 \%(n=75)$ of the nonparticipants. The mean survival time of the participants and nonparticipants was 36.1 and 29.6 months, respectively. Within PVD, the mean survival time of participants and nonparticipants was 34.4 and 27.6 months, respectively. To summarize, our article gives an overview of the survival rates in a prospective study on patients scheduled for a limb amputation. Our study sample was biased by selection and death. Participants were generally healthier than nonparticipants.
\end{abstract}

Key words: bias, cancer, complex regional pain syndrome type I, CRPS I, Kaplan-Meier curves, limb amputation, multicenter study, peripheral vascular disease, prospective study, rehabilitation, survival, trauma.

\section{INTRODUCTION}

From historical cohort studies the patient survival rate after a lower-limb amputation because of vascular problems is clearly moderate to low over time [1-12]. However, prospective studies on lower-limb amputees seldom report their survival rates, inclusion and exclusion criteria, and/or referral and dropout rates (death included) [13-20]. Thus, in these studies, little is known about bias through selective referral, number of dropouts, or mortality. The same is true for studies concerning predictors of functional outcome or quality of life after a lower-limb amputation [21-27].

In amputation research, selection bias in study samples has probably occurred but has seldom been quantified. A consequence of this selection is that amputees who managed to reach the prosthetic stage of the rehabilitation process were a small subset of those who have had an amputation. However, in research, one wants to

\footnotetext{
Abbreviations: CRPS I = complex regional pain syndrome type I, PVD = peripheral vascular disease, UMCG = University Medical Center Groningen.

* Address all correspondence to Joline C. Bosmans, PhD; Department of Rehabilitation Medicine-CB 40, University Medical Center Groningen, University of Groningen, Hanzeplein 1, PO Box 30.001, 9700 RB Groningen, the Netherlands; +31-50-3612295; fax: +31-50-3611708.

Email: j.c.bosmans@rev.umcg.nl

DOI:10.1682/JRRD.2009.06.0078
} 
generalize the results of the study to the target population. To be able to do so, researchers must use a random sample from the target population, which should have the same properties as the research population from which the research sample is drawn.

In 2003, a 4-year prospective multicenter cohort study on limb amputees was initiated at the University Medical Center Groningen (UMCG), Groningen, the Netherlands. During that prospective study, apparently, selection also occurred and a substantial number of patients referred did not fulfill inclusion criteria and, consequently, became nonparticipants. In the current study, we aimed to quantify selection by analyzing the survival rate of the participants and nonparticipants studied. In addition, the differences between these groups were analyzed.

\section{METHODS}

\section{Patients}

Patients scheduled for limb amputation were recruited for a prospective study in the northern Netherlands from November 2003 to May 2007. The survival data presented here were part of this prospective multicenter cohort study on phantom pain, phantom sensations, and residual-limb pain after a limb amputation. To ensure sufficient inflow of patients, vascular surgeons in 12 of the 13 hospitals in the northern Netherlands and surgeons of UMCG's oncological, orthopedic, and hand surgery and traumatology departments were asked to participate. Surgeons were invited to a meeting in which they were informed about the aims and logistics of the study. After the meeting, the surgeons received a written copy of the agreements made during the meeting. In addition, they were sent the inclusion and exclusion criteria, procedures for referring patients to the primary investigator, and the period they could refer potential candidates (November 2003-May 2007). Surgeons also agreed that if they decided to exclude a patient, they would send the researcher the patient's characteristics and surgical information.

During the study, we sent eight newsletters containing both the current state of affairs and a reminder to refer patients to all surgeons. In addition, we regularly telephoned the hospital wards in question. About halfway through the study, we presented information to the surgeons about the number of patients included and excluded by hospital.
Inclusion criteria for the prospective study were (1) a minimum age of 18 years, (2) an amputation level through the metacarpophalangeal or metatarsophalangeal joints or more proximal, (3) a first amputation of the limb, (4) the ability to fill in the first questionnaire before the amputation or not more than 5 days after the amputation, and (5) a sufficient command of spoken and written Dutch to fill in questionnaires. Patients were excluded if they were too ill to fill in the questionnaires or showed signs of clinical dementia to such an extent that they could not be expected to fill in the questionnaires (comorbidity).

\section{Data Entry}

We recorded patients' characteristics and the reason for, the level of, and date of amputation. Lower-limb amputations were categorized as distal (transtibial, ankle, or foot), knee disarticulation, or proximal (pelvis, hip, or transfemoral). Upper-limb amputations were categorized as distal (transradial or wrist) or proximal (forequarter, shoulder, or transhumeral); no elbow disarticulations had been performed. If patients underwent a second amputation of the same limb during the study period, we used the date of the first amputation for statistical analyses. If a patient died during the follow-up, we noted the date of death. On 1 November 2007, we investigated the survival rate of all patients referred by analyzing their records kept by participating hospitals or by consulting the patients' general practitioners.

Participants were patients who filled in questionnaires over time, and nonparticipants were followed over time through their records. Detailed outcomes of the prospective study have been reported elsewhere [28].

\section{Statistics}

We analyzed descriptive statistics using SPSS version 16.0 (Chicago, Illinois) for Windows. Differences between the participants and nonparticipants were analyzed with $t$-tests for independent samples and $\chi^{2}$-tests, as appropriate. Kaplan-Meier survival curves were drawn for the participants and nonparticipants and log-rank tests were completed. Values of $p \leq 0.05$ were considered statistically significant. Data are presented in tables, enabling detailed comparison with literature data, and in figures, providing an overview of events over time. 


\section{RESULTS}

Patients were referred from one university hospital and five general hospitals in the northern Netherlands. In total, the data of 225 patients referred were available. Of these patients, 134 (participants) were followed longitudinally by means of questionnaires during a maximum of 4 years and 91 (nonparticipants) were only followed over time through their records (16 patients refused to participate and 75 patients did not meet the inclusion criteria). Of those not meeting the inclusion criteria, 46 patients were too ill or had signs of a clinical dementia, 7 had a previous ipsilateral amputation, 19 exceeded the time interval by 5 days between amputation and the first questionnaire, 1 was younger than 18 years, and 2 patients did not speak or read Dutch (Figure 1).

The patients' characteristics and the reason for and level of amputation are summarized in Table 1. No significant differences were found in sex $(p=0.50)$ and level of amputation $(p=0.50)$ between participants and nonparticipants. Nonparticipants were significantly older than participants $(p=0.04)$. More nonparticipants $(82 \%)$ than participants (67\%) had an amputation because of peripheral vascular disease (PVD), whereas more participants had an amputation because of trauma or complex regional pain syndrome type I (CRPS I) or cancer ( $p=$ 0.03) (Table 1). Within the group of patients who had an amputation because of PVD, no significant differences in age (mean \pm standard deviation) between the nonparticipants $(71.0 \pm 12.5 \mathrm{yr})$ and participants $(67.2 \pm 13.3 \mathrm{yr})$ were found $(p=0.06)$. Of those who survived amputa-

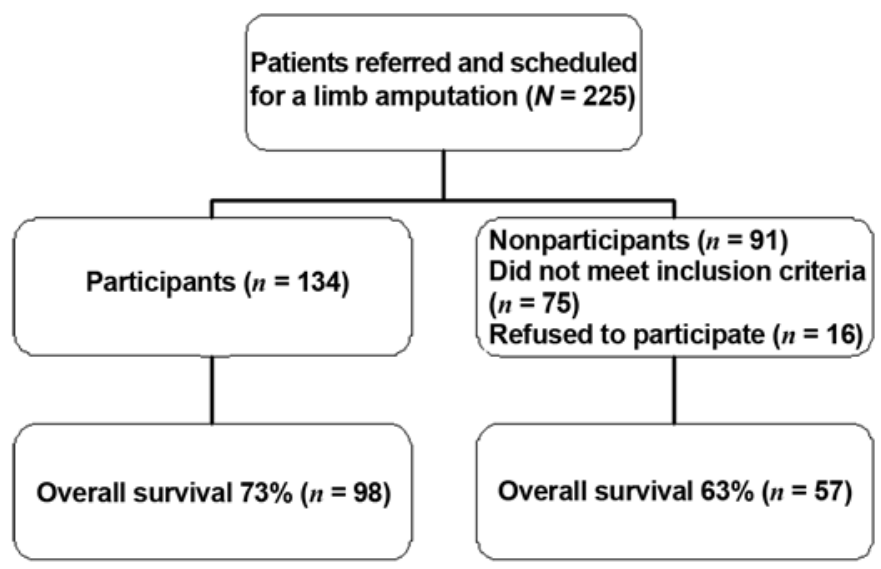

Figure 1.

Flow diagram of patients referred by hospitals. tion, no significant difference was found between the overall number of participants (73\%) and nonparticipants $(63 \%)(p=0.10)$. However, the mean survival time of participants (36.1 months) was significantly longer than that of nonparticipants (29.6 months) (log-rank test $p=$ 0.03) (Figure 2).

Of the patients who had an amputation because of PVD (165) or cancer (27), 64 percent survived, while all patients who had an amputation because of trauma or CRPS I (33) survived (log-rank test $p<0.001$ ) (Figure 3). Within the group of patients who had an amputation because of PVD, the mean survival time of participants (34.4 months) was generally longer than that of nonparticipants (27.6 months) (log-rank test, $p=0.05$ ).

All patients' mean survival time after a proximal amputation was 30.0 months, after a knee disarticulation 36.5 months, and after a distal amputation 34.9 months (log-rank test $p=0.25$ ) (Figure 4). Detailed 4-year survival data of all amputees, categorized according to sex and reason for and level of amputation, are presented in Table 2.

Within the group of amputees, 6 percent $(n=14)$ had had an upper-limb amputation that was proximal in 71 percent $(n=10)$ of the patients. The main reason for upper-limb amputation was a trauma or CRPS I $(71 \%, n=$ $10)$. One of the participants with an upper-limb amputation died from cancer 6.5 months after his amputation.

\section{DISCUSSION}

The results of the current study confirm a moderate survival rate of patients after a limb amputation. Overall, a larger percentage of the participants survived than nonparticipants.

As we have already stated, in research, one wants to generalize the study results to the target population. To be able to do so, researchers must use a random sample from the target population. Looking at the survival rates of the participants and nonparticipants found in the current study, we noted a clear bias in population: a healthier and somewhat younger population with less vascular amputations participated.

When the survival rates of the current study were compared with those of other prospective studies on amputation and phantom pain, we found that the prospective studies only reported survival of included patients, as a rule. The reported survival rate ranges from 59 to 
JRRD, Volume 47, Number 5, 2010

Table 1.

Characteristics, reason for and level of amputation, and overall number of survivors during study for participants and nonparticipants with limb amputation.

\begin{tabular}{|c|c|c|c|}
\hline \multirow[b]{2}{*}{ Variable } & \multicolumn{2}{|c|}{ Limb Amputees } & \multirow{2}{*}{$\begin{array}{c}\text { Significance Between } \\
\text { Participants \& } \\
\text { Nonparticipants ( } p \text {-value) }\end{array}$} \\
\hline & $\begin{array}{l}\text { Participants } \\
(n=134)\end{array}$ & $\begin{array}{l}\text { Nonparticipants } \\
\quad(n=91)\end{array}$ & \\
\hline Sex, \% (n) & & & 0.50 \\
\hline Female & $37(50)$ & $42(38)$ & \\
\hline Male & $63(84)$ & $58(53)$ & \\
\hline Age, mean \pm SD & $62.0 \pm 16.7$ & $66.8 \pm 17.4$ & 0.04 \\
\hline Amputation Reason, \% (n) & & & 0.03 \\
\hline PVD & $67(90)$ & $82(75)$ & \\
\hline Cancer & $13(18)$ & $10(9)$ & \\
\hline Trauma or CRPS I & $19(26)$ & $8(7)$ & \\
\hline Amputation Level, \% (n) & & & 0.50 \\
\hline Proximal Amputation & $30(40)$ & $37(34)$ & \\
\hline Knee Disarticulation & $15(20)$ & $13(12)$ & \\
\hline Distal Amputation & $55(74)$ & $50(45)$ & \\
\hline Overall Survival, \% (n) & $73(98)$ & $63(57)$ & 0.10 \\
\hline $\begin{array}{l}\text { Note: Reasons for amputation wer } \\
\text { lower limb were either proximal (p } \\
\text { either proximal (forequarter, shoul } \\
\text { CRPS I = complex regional pain sy }\end{array}$ & ut diabetes $\mathrm{m}$ & $\begin{array}{l}\text { on (PVD), cancer, or } \\
\text { instibial, ankle, or foc } \\
\text { ard deviation. }\end{array}$ & $\begin{array}{l}\text { or CRPS I. Levels of amputation of } \\
\text { els of amputation of upper limb were }\end{array}$ \\
\hline
\end{tabular}

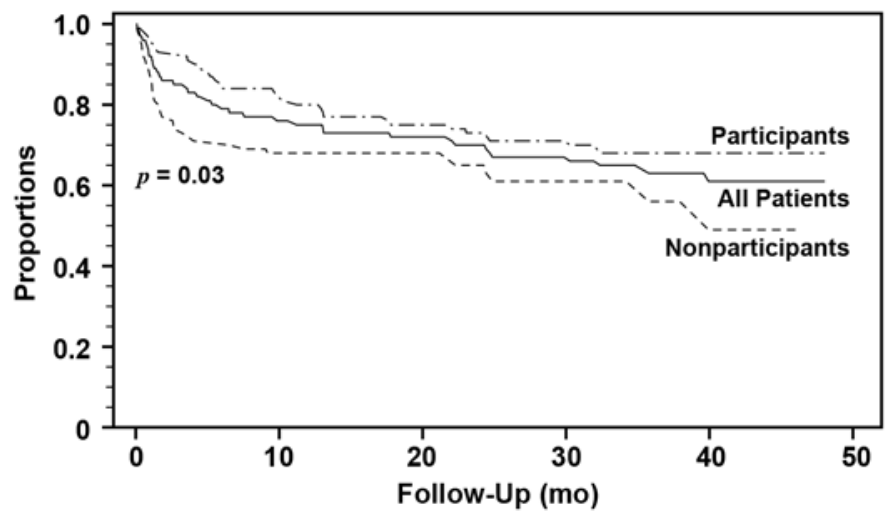

Figure 2.

Kaplan-Meier survival curves of all limb amputees (patients) $(N=$ 225), participants $(n=134)$, and nonparticipants $(n=91)$. Difference in survival between participants and nonparticipants was significant $(p=0.03)$.

92 percent 6 months after amputation [13-15,17-20] and from 59 to 67 percent 12 months after amputation [1516,18-20]. Only one study provided a 2-year follow-up [14]: the survival rate was 59 percent. The numbers of amputees who participated in these prospective studies were relatively small ( $n=21$ to $n=60$ ). The studies mainly included patients who had an amputation because

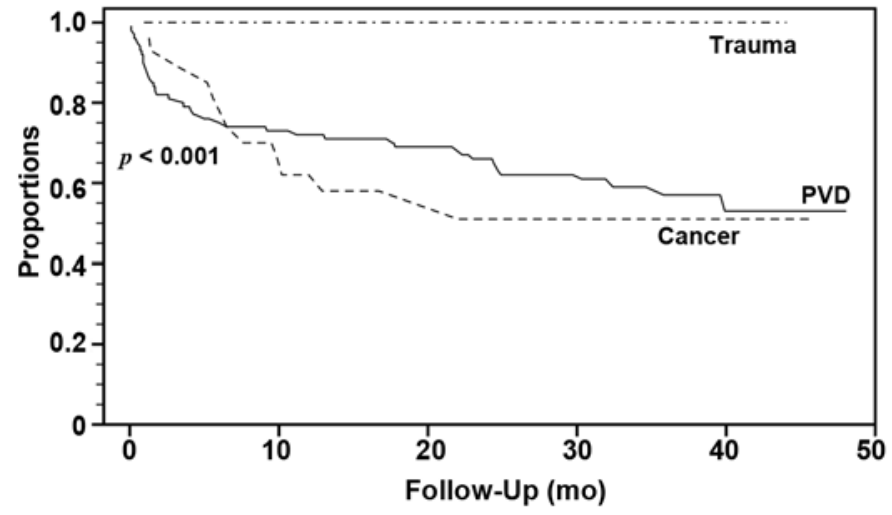

Figure 3.

Kaplan-Meier survival curves of all limb amputees according to reason for amputation (peripheral vascular disease [PVD] [ $n=165]$, cancer [ $n=27]$, or trauma or CRPS I [ $n=33]$ ). Difference in survival between trauma patients and PVD and cancer patients was significant $(p<0.001)$.

of PVD — a group of amputees having a large chance of dying relatively soon after the amputation. Furthermore, the studies seldom provided the number of patients referred to the study, the number of patients excluded and the reasons for exclusion, and the dropout rate by death [13-17,20]. Consequently, the type of selection bias that 


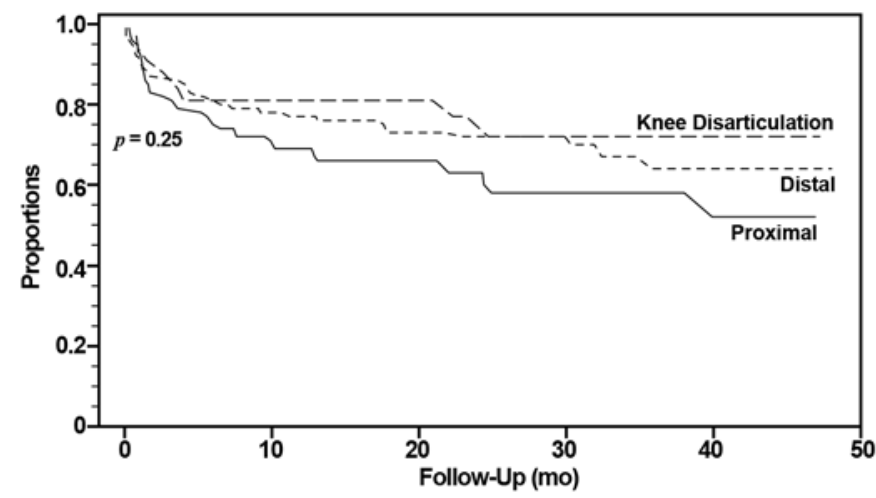

Figure 4.

Kaplan-Meier survival curves of all limb amputees according to level of amputation (proximal leg = pelvis, hip, or transfemoral and proximal arm = forequarter, shoulder, or transhumeral [ $n=74]$; knee disarticulation [ $n=32]$; or distal leg = transtibial, ankle, or foot and distal arm $=$ transradial or wrist $[n=119]$ ). Difference in survival between different levels was not significant $(p=0.25)$.

Table 2.

Survival rates in percentages of limb amputees on basis of KaplanMeier analyses for all patients referred, according to sex and reason for and level of amputation.

\begin{tabular}{lccccc}
\hline \multicolumn{1}{c}{ Variable (n) } & 6 Mo & 1 Yr & 2 Yr & 3 Yr & $\mathbf{4 ~ Y r}$ \\
\hline All Limb Amputees (225) & 79 & 75 & 70 & 63 & 61 \\
$\quad$ Participants (134) & 85 & 80 & 73 & 68 & 68 \\
$\quad$ Nonparticipants (91) & 71 & 68 & 65 & 56 & 49 \\
Sex & & & & & \\
$\quad$ Male (137) & 80 & 73 & 65 & 62 & 58 \\
Female (88) & 79 & 78 & 77 & 66 & 66 \\
Reason for Amputation & & & & & \\
$\quad$ PVD (165) & 76 & 72 & 66 & 57 & 53 \\
Cancer (27) & 78 & 62 & 51 & 51 & 51 \\
Trauma or CRPS I (33) & 100 & 100 & 100 & 100 & 100 \\
Level of Amputation & & & & & \\
$\quad$ Proximal (74) & 75 & 69 & 63 & 58 & 52 \\
Knee Disarticulation (32) & 81 & 81 & 77 & 72 & 72 \\
$\quad$ Distal (119) & 82 & 77 & 72 & 64 & 64 \\
\hline CRPS I = complex regional pain syndrome type I, PVD = peripheral vascular \\
disease.
\end{tabular}

occurred is unclear. If the same bias occurred in those studies as in our study, they probably investigated a healthier and younger subset of amputees [13-17]. Only Nikolajsen et al. reported the number of patients scheduled for an amputation ( $n=157)$, patients excluded (97/ 157) and reasons for exclusion, and dropouts (death included) [18-19]. They also reported that participants were healthier than nonparticipants. Other authors reported the number of dropouts $[17,20]$, the reason for excluding patients [13-17], or the number of patients excluded [17]. Consequently, survival data from our current study cannot be adequately compared with data of those studies. However, from the data in studies by Nikolajsen et al. [18-19], one can deduce that at least 44 percent of the excluded patients were in poorer general health than included patients. Other studies have not clearly reported how many patients were excluded for reasons of poor general health.

Concerning predictors of functional outcome after a limb amputation, excluding severely disabled patients, a prospective study found a survival rate of 85 percent within the first year [23]. Primarily, patients who went to a nursing home died, probably because of poor general health. Perhaps this study's survival rate was high compared with that of other prospective studies because of its exclusion criteria (patients not understanding the test instructions and being severely disabled without any walking ability before the amputation for reasons not related to PVD) [23]. In cross-sectional studies concerning functional outcome after a limb amputation, survival rates were not a concern because only survivors could be selected [21-22,24-27,29]. Additionally, explicit inclusion or exclusion criteria for those studies were seldom specified, except that the patients had to have undergone a lower-limb amputation and referred for a limb fitting (these patients formed a kind of convenience sample).

In historical cohort studies, an estimation of the survival rates after amputation is obtained from historical data, usually from different sources (general databases, hospital records, and medical insurance and Central Person Register databases). The total number of patients amputated is known, and the number of deaths is recorded as usual.

In certain historical cohort studies, the 1-year survival rates ranged from 49 to 73 percent $[1-2,4,8,10,12,30]$ and the longer term (interval 5-year) survival rates were 26 percent [1-2,12]. The number of patient records in these historical cohort studies was large ( $n=174$ to $n=$ 21,520) [1-2,4,6,8-11,30].

The limitation of the current study is that the number of referred patients scheduled for a lower-limb amputation was considerably smaller than expected. On the basis of earlier Dutch amputation studies [3,21], the population of the northern Netherlands (comprising the provinces of 
Groningen, Friesland, and Drenthe) [31], and the number of participating hospitals, an estimated 150 to 170 new patients with a lower-limb amputation could be referred to the current study each year. Despite all efforts, only 35 to 40 percent ( $n=211$, inclusion period $31 / 2$ years) of the estimated population of lower-limb amputees in the northern Netherlands were referred, indicating a considerable selection bias. Surgeons from only six hospitals referred patients. The reasons why surgeons did not participate in the study, despite having previously indicated a willingness to participate and despite regular reminders, have remained unclear.

Selection bias has probably not occurred for upperlimb amputees. Of the 225 patients referred, 14 patients were scheduled for or had undergone an upper-limb amputation (through wrist or more proximal), of whom 10 patients had experienced a trauma or CRPS I. This result means an incidence of 0.2/100,000 in the northern Netherlands. Our rate corresponds with the incidence rate of traumatic upper-limb amputations in Sweden, Norway, and the United States, where rates of $0.1,0.1$, and 0.4 / 100,000 inhabitants, respectively, have been reported [32-34]. In the northern Netherlands, patients with an upper-limb amputation are mainly treated at UMCG. We recommend that future research more clearly report inclusion and exclusion criteria and referral rates.

\section{CONCLUSIONS}

In this article, we have given survival rates in a prospective study on patients scheduled for a limb amputation. Our study sample of patients is biased by selection and death. Participants were generally healthier than nonparticipants.

\section{ACKNOWLEDGMENTS}

\author{
Author Contributions: \\ Study concept and design: J. C. Bosmans, P. U. Dijkstra, \\ J. H. B. Geertzen. \\ Acquisition of data: J. C. Bosmans. \\ Analysis and interpretation of data: J. C. Bosmans, P. U. Dijkstra. \\ Drafting of manuscript: J. C. Bosmans. \\ Critical revision of manuscript for important intellectual content: \\ P. U. Dijkstra, H. J. Hoekstra, J. H. B. Geertzen. \\ Statistical analysis: J. C. Bosmans, P. U. Dijkstra. \\ Obtained funding: J. C. Bosmans, J. H. B. Geertzen. \\ Administrative, technical, or material support: J. C. Bosmans, \\ P. U. Dijkstra, H. J. Hoekstra, J. H. B. Geertzen.
}

Study supervision: P. U. Dijkstra, J. H. B. Geertzen.

Financial Disclosures: The authors have declared that no competing interests exist. The authors alone are responsible for the content and writing of the article.

Funding/Support: This material was based on work partially supported by grants (no grant numbers) from the OIM Foundation Assen, the Netherlands, and the Beatrixoord North Netherlands Foundation (210.055, part 2), Haren, the Netherlands.

Additional Contributions: We would like to thank all patients, surgeons and their secretaries, physiotherapists, rehabilitation physicians, ward doctors, and all other persons from the hospitals in the northern Netherlands: UMCG, Martini Hospital in Groningen, Wilhelmina Hospital in Assen, Hospital Nij Smellinghe in Drachten, Refaja Hospital in Stadskanaal, and St. Lucas Hospital in Winschoten, for their active participation in this study, as well as general practitioners and their secretaries in the provinces of Groningen, Friesland, and Drenthe. Institutional Review: Medical ethical committees of all participating hospitals approved the study protocol.

Participant Follow-Up: The authors do not plan to notify the study subjects of the publication of this article because of the lack of contact information.

\section{REFERENCES}

1. Pohjolainen T, Alaranta H. Ten-year survival of Finnish lower limb amputees. Prosthet Orthot Int. 1998; 22(1):10-16. [PMID: 9604271]

2. Ebskov B. Relative mortality and long term survival for the non-diabetic lower limb amputee with vascular insufficiency. Prosthet Orthot Int. 1999;23(3):209-16. [PMID: 10890595]

3. Pernot HF, Winnubst GM, Cluitmans JJ, De Witte LP. Amputees in Limburg: Incidence, morbidity and mortality, prosthetic supply, care utilisation and functional level after one year. Prosthet Orthot Int. 2000;24(2):90-96.

[PMID: 11061195] DOI:10.1080/03093640008726531

4. Feinglass J, Pearce WH, Martin GJ, Gibbs J, Cowper D, Sorensen M, Henderson WG, Daley J, Khuri S. Postoperative and late survival outcomes after major amputation: Findings from the Department of Veterans Affairs National Surgical Quality Improvement Program. Surgery. 2001; 130(1):21-29. [PMID: 11436008] DOI:10.1067/msy.2001.115359

5. Cruz CP, Eidt JF, Capps C, Kirtley L, Moursi MM. Major lower extremity amputations at a Veterans Affairs hospital. Am J Surg. 2003;186(5):449-54. [PMID: 14599605] DOI:10.1016/j.amjsurg.2003.07.027

6. Aulivola B, Hile CN, Hamdan AD, Sheahan MG, Veraldi JR, Skillman JJ, Campbell DR, Scovell SD, LoGerfo FW, Pomposelli FB Jr. Major lower extremity amputation: Outcome of a modern series. Arch Surg. 2004;139(4):395-99. 
[PMID: 15078707]

DOI:10.1001/archsurg.139.4.395

7. Ploeg AJ, Lardenoye JW, Vrancken Peeters MP, Breslau PJ. Contemporary series of morbidity and mortality after lower limb amputation. Eur J Vasc Endovasc Surg. 2005; 29(6):633-37. [PMID: 15878543]

DOI:10.1016/j.ejvs.2005.02.014

8. Dillingham TR, Pezzin LE, Shore AD. Reamputation, mortality, and health care costs among persons with dysvascular lower-limb amputations. Arch Phys Med Rehabil. 2005; 86(3):480-86. [PMID: 15759232] DOI:10.1016/j.apmr.2004.06.072

9. Kulkarni JR, Pande S, Morris J. Survival rates in dysvascular lower limb amputees. Int J Surg. 2006;4(4):217-21. [PMID: 17462354] DOI:10.1016/j.ijsu.2006.06.027

10. Bates B, Stineman MG, Reker DM, Kurichi JE, Kwong PL. Risk factors associated with mortality in veteran population following transtibial or transfemoral amputation. J Rehabil Res Dev. 2006;43(7):917-28. [PMID: 17436177] DOI:10.1682/JRRD.2006.03.0030

11. Heikkinen M, Saarinen J, Suominen VP, Virkkunen J, Salenius J. Lower limb amputations: Differences between the genders and long-term survival. Prosthet Orthot Int. 2007; 31(3):277-86. [PMID: 17979013]

DOI:10.1080/03093640601040244

12. Bo Ebskov L. Dysvascular amputations and long-term survival in a 20-year follow-up study. Int J Rehabil Res. 2006; 2(4)9:325-28. [PMID: 17106350]

13. Jensen TS, Krebs B, Nielsen J, Rasmussen P. Phantom limb, phantom pain and stump pain in amputees during the first 6 months following limb amputation. Pain. 1983;7(3): 243-56. [PMID: 6657285] DOI:10.1016/0304-3959(83)90097-0

14. Jensen TS, Krebs B, Nielsen J, Rasmussen P. Immediate and long-term phantom limb pain in amputees: Incidence, clinical characteristics and relationship to pre-amputation limb pain. Pain. 1985;21(3):267-78. [PMID: 3991231$]$ DOI:10.1016/0304-3959(85)90090-9

15. Bach S, Noreng MF, Tjéllden NU. Phantom limb pain in amputees during the first 12 months following limb amputation, after preoperative lumbar epidural blockade. Pain. 1988;33(3):297-301. [PMID: 3419837]

DOI:10.1016/0304-3959(88)90288-6

16. Jahangiri M, Jayatunga AP, Bradley JW, Dark CH. Prevention of phantom pain after major lower limb amputation by epidural infusion of diamorphine, clonidine and bupivacaine. Ann R Coll Surg Engl. 1994;76(5):324-26. [PMID: 7979074]

17. Pinzur MS, Garla PG, Pluth T, Vrbos L. Continuous postoperative infusion of a regional anesthetic after an amputation of the lower extremity. A randomized clinical trial.
J Bone Joint Surg Am. 1996;78(10):1501-5.

[PMID: 8876577]

18. Nikolajsen L, Ilkjaer S, Christensen JH, Krøner K, Jensen TS. Randomised trial of epidural bupivacaine and morphine in prevention of stump and phantom pain in lowerlimb amputation. Lancet. 1997;350(9088):1353-57.

[PMID: 9365449]

DOI:10.1016/S0140-6736(97)06315-0

19. Nikolajsen L, Ilkjaer S, Krøner K, Christensen JH, Jensen TS. The influence of preamputation pain on postamputation stump and phantom pain. Pain. 1997;72(3):393-405. [PMID: 9313280] DOI:10.1016/S0304-3959(97)00061-4

20. Lambert AW, Dashfield AK, Cosgrove C, Wilkins DC, Walker AJ, Ashley S. Randomized prospective study comparing preoperative epidural and intraoperative perineural analgesia for the prevention of postoperative stump and phantom limb pain following major amputation. Reg Anesth Pain Med. 2001;26(4):316-21. [PMID: 11464349]

21. Rommers GM, Vos LD, Groothoff JW, Schuiling CH, Eisma WH. Epidemiology of lower limb amputees in the north of the Netherlands: Aetiology, discharge destination and prosthetic use. Prosthet Orthot Int. 1997;21(2):92-99. [PMID: 9285952]

22. Hermodsson Y, Ekdahl C, Persson BM. Outcome after trans-tibial amputation for vascular disease. A follow-up after eight years. Scand J Caring Sci. 1998;12(2):73-80.

[PMID: 9801627] DOI:10.1080/02839319850162995

23. Schoppen T, Boonstra A, Groothoff JW, De Vries J, Göeken LN, Eisma WH. Physical, mental, and social predictors of functional outcome in unilateral lower-limb amputees. Arch Phys Med Rehabil. 2003;84(6):803-11. [PMID: 12808530] DOI:10.1016/S0003-9993(02)04952-3

24. Gallagher P, MacLachlan M. The Trinity Amputation and Prosthesis Experience Scales and quality of life in people with lower-limb amputation. Arch Phys Med Rehabil. 2004; 85(5):730-36. [PMID: 15129396]

DOI:10.1016/j.apmr.2003.07.009

25. Geertzen JHB, Bosmans JC, Van der Schans CP, Dijkstra PU. Claimed walking distance of lower limb amputees. Disabil Rehabil. 2005;27(3):101-4. [PMID: 15823990] DOI:10.1080/09638280400009345

26. Meulenbelt HE, Geertzen JHB, Dijkstra PU, Jonkman MF. Skin problems in lower limb amputees: An overview by case reports. J Eur Acad Dermatol Venereol. 2007;21(2): 147-55. [PMID: 17243947] DOI:10.1111/j.1468-3083.2006.01936.x

27. Bosmans JC, Suurmeijer TP, Hulsink M, Van der Schans CP, Geertzen JHB, Dijkstra PU. Amputation, phantom pain and subjective well-being: A qualitative study. Int J Rehabil 
JRRD, Volume 47, Number 5, 2010

Res. 2007;30(1):1-8. [PMID: 17293714]

DOI:10.1097/MRR.0b013e328012c953

28. Bosmans JC, Geertzen JHB, Post WJ, Van der Schans CP, Dijkstra PU. Factors associated with phantom limb pain: A 31/2-year prospective study. Clin Rehabil. 2010;24(5): 444-53. [PMID: 20442256] DOI:10.1177/0269215509360645

29. Meulenbelt HEJ, Dijkstra PU, Jonkman MF, Geertzen JHB. Skin problems in lower limb amputees: A systematic review. Disabil Rehabil. 2006;28(10):603-8. [PMID: 16690571] DOI:10.1080/09638280500277032

30. Eskelinen E, Lepäntalo M, Hietala EM, Sell H, Kauppila L, Mäenpää I, Pitkänen J, Salminen-Peltola P, Leutola S, Eskelinen A, Kivioja A, Tukiainen E, Lukinmaa A, Brasken P, Railo M. Lower limb amputations in Southern Finland in 2000 and trends up to 2001. Eur J Vasc Endovasc Surg. 2004;27(2):193-200. [PMID: 14718903] DOI:10.1016/j.ejvs.2003.10.011

31. Centraal Bureau voor de Statistiek [Internet]. Den Haag (the Netherlands): Centraal Bureau voor de Statistiek; 2010 [cited 2009 Feb 15]. Available from: http://www.cbs.nl/nl-NL/menu/home/default.htm/.

32. Nylander G, Vilkki S, Ostrup L. The need for replantation surgery after traumatic amputations of the upper extrem-
ity-An estimate based upon the epidemiology of Sweden. J Hand Surg Br. 1984;9(3):257-60. [PMID: 6334710] DOI:10.1016/0266-7681(84)90037-8

33. Atroshi I, Rosberg HE. Epidemiology of amputations and severe injuries of the hand. Hand Clin. 2001;17(3):343-50. [PMID: 11599204]

34. Dillingham TR, Pezzin LE, MacKenzie EJ. Limb amputation and limb deficiency: Epidemiology and recent trends in the United States. South Med J. 2002;95(8):875-83.

[PMID: 12190225]

Submitted for publication June 18, 2009. Accepted in revised form February 16, 2010.

This article and any supplementary material should be cited as follows:

Bosmans JC, Geertzen JHB, Hoekstra HJ, Dijkstra PU. Survival of participating and nonparticipating limb amputees in prospective study: Consequences for research. J Rehabil Res Dev. 2010;47(5):457-64.

DOI:10.1682/JRRD.2009.06.0078 